\title{
Governance of the Russian Higher Education System in the Light of an Innovative Development Path Selected
}

\author{
Sergey N. Postnikov \\ Tomsk State University of Architecture and Building, Russian Federation \\ Nikolay N. Minaev \\ Natural Resources Institute, Tomsk Polytechnic University, Russian Federation \\ *Corresponding Email: nnminaev@mail.ru \\ Aliona V. Andrienko \\ Institute of Cadastre, Economy and Engineering Systems in Construction \\ Tomsk State University of Architecture and Building, Russian Federation
}

Doi:10.5901/mjss.2015.v6n6s7p228

Abstract

This article analyzes the particularities in governance of the Russian higher education system in the light of an innovative development path selected. Authors consider internal and external challenges of the Russian higher education, as well as analyze management practices and regulations of the state level. The study applies systemic and institutional methods and approaches. Structural and functional analyzes revealed trends revealing the multi-layered problems of management of innovation development of vocational education in Russia. The authors reject the idea of universal models and solutions, offering a conceptual approach to the design and implementation of multi-level variable system of vocational education management instead. Further on, the article suggests the innovative elements of the management model of the higher education system.

Keywords: education management, management models, situational approach, innovative practices

\section{Conditions of Reforming the Educational System}

Reforming of the Russian educational system in general and higher education in particular, is an objectively necessary process, as an adequate response to the dynamics of society and the external and internal challenges of the time allocated in figure 1. External factors are defined by the modern conditions of the subjective nature (Popov et al., 2015), such as global and civilizational crisis, biosphere-ecological crisis, and the ideological (i.e. world outlook) crisis.

The fundamental change in the situation is possible if the institutional changes and structural reforms are implementation through the integration of public educational systems. In this context, the increase in the number of countries participating in the Bologna process should be regarded as an objective and timely process that able to improve the quality of interaction between actors. But at the same time, such issues being raised as improvement of the competitiveness of domestic universities in the world community, the fundamental changes in approaches to performance assessment and rating of high schools, the improvement of the strategic guidelines.

It should be noted that the need for the integration of educational systems is necessary but not sufficient condition to overcome the crisis. There are a number of immediate steps, which are beyond the scope of this paper. Let us go back to ordering the challenges. 


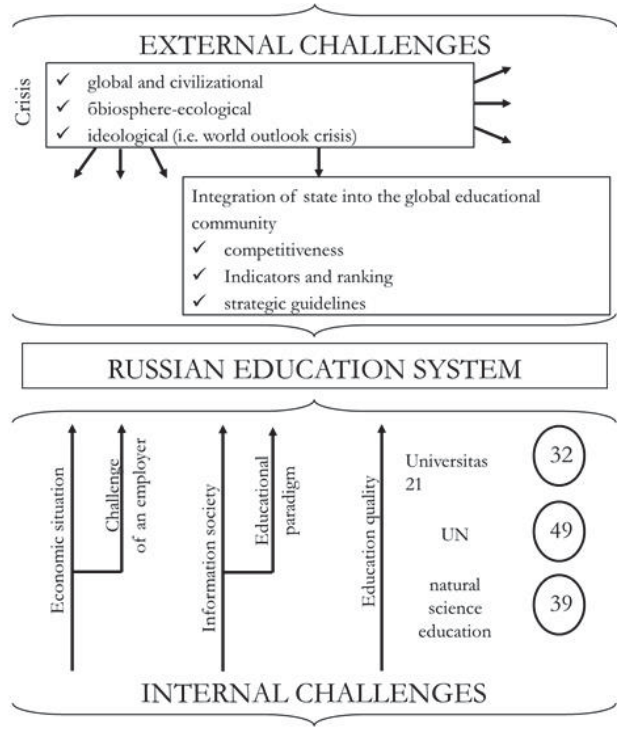

Figure 1. Russian state education system in these conditions

Internal challenges partly arise due to external factors; however, there are a number of specific features. First of all, it is an incomplete transition from a planned to a market economy, which leads to 'the problem of employer': an order for training of specialists is created by the state (i.e. the planning approach) and the work is given spontaneously, in accordance with the requirements of the market.

Another challenge is related to fundamental changes in the methodological foundations of education. For example, modern informational state of society, defined by the rapid growth of production and the intense accumulation of knowledge, leads, ultimately, to an unprecedented earlier rapid change of technologies. This sets the unreachable targets in front of the education system, since it is too conservative, remaining virtually unchanged over the last century. A change of educational paradigm is required, the first step of which is the introduction of competence-based approach. This step has far-reaching implications that will affect virtually all aspects of education.

Finally, we shall consider the fall of the education quality. The fact being recognized by the professional community, especially since the fall of the quantitative level of the Unified State Exam - USE (today it is evident via objective indicators) and its level of organization in general. However, we recall that, according to the 'Universitas 21' rating, which is based on an estimate of the level of national education evaluated by the international consortium of leading academic universities in the world, Russia over the last few years takes 'honorable' $32^{\text {nd }}$ place. The United Nations ranking, the latter of which is published in 2012, suggests the national educational system of Russia qualifies for $49^{\text {th }}$ place.

In many ways, this fact is explained by sharp decline over the last 20 years in demand of the engineering specialization among high school graduates (according to statistics of the Ministry of Education of Russia, engineering accounts for 3-5\% of applicants), and this, in turn, is a direct consequence of the fall of the real sector of the economy, its level of innovation and technological backwardness and a low level of modern technology. An illustrating example are the data of the Center for Educational Quality Assessment Russia of 2009, which shows that national education system ranks $38^{\text {th }}$ out of 65 countries in mathematical education and $39^{\text {th }}$ for natural sciences. We must admit that there is still no statistics evaluating the quality of higher education, as there is no mechanism developed. However, it is unlikely that assessment of the situation in this area will be optimistic.

Thus, in the present conditions the development of the education system requires non-trivial and unprecedented steps that have no analogues. Their effectiveness depends primarily on the effectiveness of management. Therefore, the range of problems related to the management of education at different stages and levels of the hierarchy is becoming increasingly important. 


\section{Higher Education Management and Policy}

In terms of pedagogical approach, issues of education management are studied well enough, but mostly in the field of principles of educational process organization, innovation, organizational change, management of educational institutions. Of particular interest are the works of Burov et al. (2014), Dneprov (2006), Kuzminova et al. (2013), Titova (2011), Schedrovitsky (2001), devoted to the analysis of best management practices at the municipal, regional and federal level, as well as an international experience studied by Barber et al. (2012), De Corte (2014), Starik et al. (2010), Clark (2011), Audebrand (2010). Given that these works deserve self-study, we only present them concisely.

Identifying the driving forces of internal reforms in the universities, based on the concept and the theory of involvement of interested parties, Kuzminova et al. (2013) state that the Russian universities express a 'treaty of noninvolvement', the essence of which is to abandon the changes. Authors further analyze the changes in the structure of the higher education system, inherited by Russia from the Soviet Union, describe the types of institutions of higher education arising as a result of these changes. Burov et al. (2014) describe the new practice of public-public administration in the education system with the involvement of society to the managerial decisions. In their view, the involvement of citizens in the discussion of management solutions is built on a special technology - crowdsourcing. This management practice still needs its institutional design, given that the activities of the administration bodies has still a sporadic nature.

Titova (2011) describes in the model of strategy formulation for universities, which are composed of relatively independent parts (i.e. departments, offices, institutions, etc.) being at different levels of development and can have own programs, facing a problem of ensuring a single development path of the university altogether. The problem of the interrelation between classical and research university models, as well as the changes taking place in the modern classical university put in the work of Schedrovitsky (2001). He proposed a new form of organization of collective thinking and activity - organizational-activity games that combine the properties of educational and business games and methodological-intellectual discourse, which are widely used in the educational institutions' management practice.

It should be noted that the Russian academic community was engaged in the study of university management immediately after the radical socio-economic changes of the early 90-ies of the last century, when the new conditions of existence of high school began to dictate the need for new organizational approaches.

Development of the issues of university management was stimulated from the beginning of the 1990 s by the federal education authorities. This relates to the target program "Universities of Russia", the program "Integration", the federal program of development of education. At the municipal and regional level, a number of projects have been implemented, such as "Interaction of universities and schools in an open educational space", "Study of Educational Innovation: phenomenology, typology, topology", "Development and implementation of models of cooperation between institutions of higher vocational and general education for the implementation of educational programs of high school, focused on the development of giftedness in children and adolescents based on the distance of the school at the National Research University in the following academic areas: humanities, natural sciences, physics and mathematics", "Corporate culture of classical university: the role in the formation of professional and personal identity of the graduate", "The search for new models of socio-economic organization: university as the organizational paradigm of the knowledge economy" and others.

In addition, the concept of university management has been actively developed in Russia with the help of funds of various international organizations. Among them are Tempus - TACIS of the European Commission, including a subprogram on university management, the program "Improvement of management in higher education", funded by the National Training Foundation of the World Bank loan for Reconstruction and Development, the program "Support for the administration of higher education institutions" of the International Council for Research and Exchanges Board (USA), Salzburg Seminar program (funded by the United States), the program "University strategic planning in the context of the regionalization of higher education in Russia". Team of university employees involved in the implementation of the relevant projects have made a significant contribution to the development of university management, the formation of its technology and the solution of certain problems of university management.

In general, there are four university models: Bologna, Paris, Humboldt and entrepreneurial. Law students to defend their interests, primarily against teachers, founded University of Bologna in 1088. The main purpose of such a university the transfer of practically applicable knowledge. The rector was chosen from among students. This model, which was the main characteristic of the practical orientation of education, has spread to Italy and Spain.

The University of Paris was founded in 1208 by philosophers, students and masters to ensure the conditions for intellectual pursuits. Autonomy of the university was challenged by the city government, from which the University of Paris was seeking protection, primarily, with the Pope. The rector was chosen from among the master students of philosophy. The essence of this model is the formation for the sake of education. Standards for entry and stay in the university 
corporation of this type were very high.

The Humboldt University of Berlin was established in 1809 with the main purpose of education of citizens in the spirit of scientific research. At the same, a close relationship between research and teaching postulated. The university was managed by professorial senate, which elected the rector of among the professorial community. This model of the university served as a model to create universities in the United States and Russia.

The entrepreneurial university is the result of a combination of Humboldt principles and corporate governance model. Managed by the president and controlled by the Board of Trustees. The Board of Trustees is formed from authoritative public figures, mainly entrepreneurs. The university is engaged in education, research and commercial advancement of knowledge. The main task is the maximum capitalization of intellectual authority of departments. At the same time, this problem is in contradiction with the need to maintain high intellectual standards and authority of departments. As a result, the entrepreneurial university shows a strong position of the administration.

It is difficult to pinpoint the most effective of these models because there is no mechanism for assessing the models of different goals and objectives. Meanwhile, it is necessary to draw attention to the fact that the methods of pedagogical theory and practice are not sufficient for the development of the concept of education management. To form the development strategy of education as a system of general and educational organizations in particular, it is necessary to expand the field of research and to integrate an experience of sociology, law, psychology and economics.

However, the scope of scientific research on education management as an integrative phenomenon is so young that scientific school in the classical sense is not yet developed, so long as there is no systematic and comprehensive study of these issues. The authors hope to make a contribution to solving the problems raised.

\section{The Strategic Goal and the Challenges of Achievement}

Vector of modernization being set by the state program on "The development of education for 2013-2020", which is based on the Law on Education in the Russian Federation, is in line with the Concept of long-term socio-economic development of the Russian Federation (Figure 2).

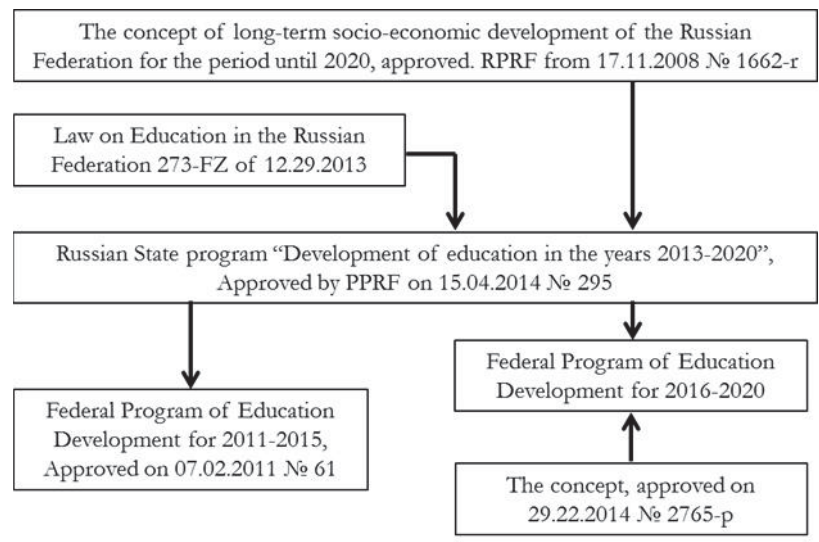

Figure 2. Normative bases of education system modernization

In turn, the components of the state program are two of the federal target program of education development for periods 2011-2015 and 2016-2020.

State program of education development until 2020 in respect of sub-programme 1 "Development of Vocational Education" sets the goal of a significant increase in the contribution of vocational education in the socio-economic modernization of Russia, in raising its global competitiveness, ensuring demand of every student by the economy and society. Its achievement has set the higher education system a number of tasks, including: the formation of a differentiated network of educational institutions (while taking into account the peculiarities of the regions), modernization of the structure and content of the programs, the development and implementation of mechanisms for financing and encouraging the formation of the system of continuous education.

However, analysis of the preliminary results of the implementation of the federal target program on "Development 
of Education for 2011-2015" shows that some of the development scenarios for the organizations that have been set at the first stage of change cannot be brought to the new management models, as situation has changed dramatically with the new Education Act and many regulations Acts following. Is it is mentioned in the Concept of the Federal Target Program of Education Development for 2016-2020, this led to fact that new federal target program in 2016 will have to start with bringing the obtained models in accordance with the legislation changed, and only then can we count on success of their implementation.

This mismatch has objective reasons, related primarily to the fact that we are dealing with a very complex, multiparameter, and, in fact, a conservative system. Hence, as already mentioned, any evaluation whatever single pointed it is, spreads like a wave, and influences, in the end, all levels of the system. This creates many difficulties associated with forecasting.

Indeed, since there is no integrated system model that would include characteristics and interrelation of subjects of the educational system, the processes occurring in it, mechanisms and tools to ensure its planned development, it is extremely difficult, if possible at all, to predict the results. In practice, there is a kaleidoscope of effects and results at different levels of the education system management, from one or another step on the way of reforms, regardless of its scale. It is possible that some relatively small and seemingly local action can give a global system-wide effects, and vice versa.

However, the very possibility of establishing such a general model is questionable. A variety of goals, objectives and educational organizations that being addressed in such a multicultural, multi-ethnic, geographical extent and economically diverse country as Russia, leaves no hope for the existence of a universal approach to the management of both the higher education system and its structural units. Moreover, the currently accepted 'universal' solutions only exacerbate the existing problem situations, such as: reducing the number of teaching staff in the background of the expected population growth; unjustified typology and structure of educational institutions; ineffectiveness of planning and normative financing; lack of monitoring of the quality of educational services and other issues.

The situation is aggravated by the lack of common goals, that is, since the processes of modernization forced to affect every single component of the education system, from its constituent entities to deep internal processes, to the forefront come the issues of development management. It should be viewed in two ways, both by the reformer, which in this case is the state, and reformed, that is, directly the schools. In fact, we see a complete mismatch of actions of the parties. An example is the existing so-called 'system of monitoring the effectiveness of higher education institutions'.

Its goal is in line with development programs and is rather clear - the diagnosis. It is required to assess the situation, determine the initial conditions of the organizations of higher education and to trace the subsequent dynamics in the process of their development. But not in vain around the evaluation of the effectiveness of such universities there are disputes and discussions, leading sometimes to serious confrontation of government agencies and educational community. There are many fundamental issues related to performance and their compliance with the actual state of affairs, the effects of performance / failure of an indicator, and so on. The state, represented by the Ministry of Education of Russia cannot answer these and many other contemporary challenges and the confirmation are frequent changes in the list of indicators and methods of evaluation of the monitoring procedure. It can be noted that the state is actively looking for a more objective way of assessing the effectiveness of universities.

For its part, institutions of higher education are faced with a number of pressing issues: ensuring the effectiveness of operations, the development of concrete steps on the monitoring results, productive realization of ideas on modernization and sustainable long-term development. At the moment, most of the decisions are taken on an intuitive level of management, or the all-Russian, typical schemes being used. Coherence within the system of education cannot be overestimated. One can bring a surprising, but, in fact, the correct analogy: the treatment of a neglected disease. It will be successful only in case of a concerted action of the doctor and the patient. Only the professionalism of the first and active support of the second will have a favorable result.

The list of problems, not limited to those mentioned above, is designated as follows: completeness and accuracy of forecasting; requirements of unique and unprecedented decisions; the need to combine the efforts of actors involved in the achievement of common goals.

\section{Methodology of Searching for Solutions}

Solution of the mentioned problems is proposed to build on the basis of an indicated above simulation of interaction of subjects of education, motivated to be active to achieve the objectives of the education system. In order for such models to be able to take into account the diversity of the subjects, a wide range of cooperation, the different types and possible trajectories of development, regional features and more, there is a need to build a fundamentally new system of 
alternative models of management in higher education, including two interdependent and mutually reinforcing blocks: the higher education and the continues professional education. Thus, for the first time an attempt on rejection of the idea of universal models and solutions is given, in favor of a conceptual approach to the design and implementation of multi-level variable system of vocational education management in all its diversity.

When developing such an approach one should take into account the conditions in which it can be implemented, as the current situation in education is characterized by not only the dynamism and uncertainty, but also the transition from single local projects to the systemic ones, the methodological changes. Let us consider the external and internal aspects of these changes.

The external aspect. The education sector is not an isolated system. On the contrary, it is related to other areas of human activity: economy, labor market, social sphere, the political situation and so on. Therefore, one needs to find out which areas have a significant inverse effect on the education system (in other words, are a significant factor) and to determine the patterns of their development.

The internal aspect. According to Federal Law 273, "Law on Education in the Russian Federation", the education system is a set of interacting components: institutional (i.e. educational organizations of various kinds), governments, regulatory and methodological base. Consequently, one needs to carefully analyze the scheme of their interactions as to identify 'weak' units and planning of possible restructuring of network linkages and their optimization.

\section{Stages of Implementation and Design Features of the Model}

Now that the goal, novelty and conditions of construction of multi-level variable system of education management is clear, let us give a closer look at the stages of its implementation.

1. Itemizing the structure. After studying the above described features of the internal and external aspects, the next level of consideration will be the organization of higher education, which, in turn, is also a set of subsystems: physical infrastructure, human resources, financing system, management structures, and the like. It is necessary to identify the key characteristics and patterns of interaction of these subsystems with the purpose of the typology of higher education institutions and harmonization of the problems they are facing. The management structure of the educational organization has signs of a mechanistic or organic structure. The mechanistic structure of the educational organization is characterized by a rigid hierarchy and subordination, standardization of procedures and rules, a clear division of rights and responsibilities, the centralization of decision-making. In contrast, organic structure is flexible, decentralized, and preference is given to the teamwork. The educational system in reality are rarely organizations of purely mechanistic or purely organic types, any structure can be described as a combination of both types in different proportions.

2. Development scenario. The diversity of universities involves diversity of scenarios of their development. However, the principles of such scenarios should be the same: it is necessary to specify the main vector of development, to evaluate the potential resources and to generate a control strategy. Naturally, each of these three components for schools of different types will be different. In particular, the direction is determined by the tasks that are different, for example, the federal university and a regional technical college. Differ the resource needs and organizational approaches. However, all higher education institutions, which are all the same type of a single enlarged - organizations of higher education - some of the basic scenario will be the same. But there will be variability, depending on the type of institution. To describe such a scenario with a two-stage selfintersecting path requires a comprehensive analysis realized in high schools of different types of approaches through the use of integrated development programs, self-examination materials, the results of monitoring, and other relevant documents.

3. Rationale. From the point of view of scientific systematic approach to the problem, it is not enough to describe and offer some development scenarios for different types of high schools. An evidence base of their effectiveness is needed. It can be based on quantitative measurements and the calculation of the dynamics of their change in the course of implementation of various activities under the proposed scenario.

4. Return to the system. Typologisation, analysis of the university activities, the development of scenarios and the experimental calculation of their implementation will enable to come back in this object of research at the top level review of the education system across the state and move on to the main subject - the management bodies. The latter, having at its disposal an overall picture of development scenarios and the criteria map for their selection, will be able clearly and purposefully implement the education policy, from the decisions on the composition and differentiation of higher education institutions in a given region, their targeted funding for certain items, the formation of clear principles of change in regulatory and methodological framework and 
ending with an objective assessment of the effectiveness of the governance structures of universities and their operational reorganization, if necessary. (Figure 3)

Thus, work on the design and construction of education management system should include the following steps

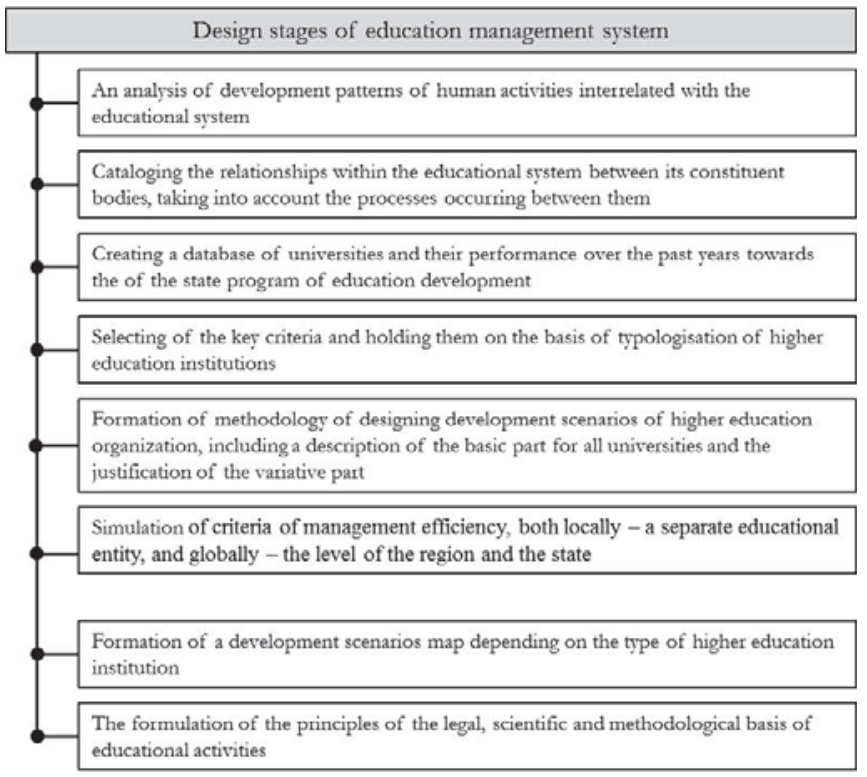

Figure 3. Stages of education management system design

On this basis, the authors solve the problem of creating alternative models of management, development and interaction of entities of the education system and the processes occurring in the latter, including: the system of development scenarios elaboration; forecasting tools, and evaluation of the implementation of these scenarios; funding mechanisms and incentives of high schools; arrangements with other levels of educational organizations and employers in the framework of continuous education; algorithm of managerial decisions' formation.

In constructing the model as it relates to the construction of the scenario of university development, one should consider not only the large number and diversity of resources used, but also an extremely wide range of closely interrelated processes: training, research, quality assurance, staffing, funding, cooperation and many others. It is an extremely difficult and complex task to consider these features in the organization of management, the importance of the successful solution of which cannot be overestimated. allow for:

The above listed involves the use of the situational approach with the elements of simulation modeling, which will

- a comprehensive solution to the problems with the identification and analysis of relevant factors that will determine the priority of strategic moves and tactical activities, take into account all aspects of the education system in the context of achieving the goals set;

- flexible scheduling with the possibility to expand its horizons, if necessary;

- ongoing monitoring of the implementation of the model on the basis of a map of indicators that will assess the effectiveness of the results of the activities on stages at predetermined time intervals.

Today, it is clear that the education system cannot have the sole and equally effective methods of management, because different the best results achieved using different strategies in circumstances.

Using situational approach in decision-making within the educational organization can take place in several stages. Firstly, it is necessary to examine a real model of a particular organization, and secondly, to evaluate the effect of all existing management models. For example, the most effective might be the management model of scientific activity, thus it would be wise to apply it to other areas in the last stage. 
Among the elements of studying the real model of an educational organization can be determined:

- quantitative indicators that formally characterize the organization (e.g. number of ongoing areas of training, the number of the faculty members given by the number of students, etc.);

- technologies (e.g. administrative, educational, research, distance, etc.);

- environment (e.g. regional and economic particularities, national, etc.);

- management strategy, as reflected in development programs and roadmaps, programs to increase competitiveness, etc.;

- interaction between the university management in general, between the heads of departments and faculty members.

The links between all these variables are of complex and ambiguous nature. In our case, it is advisable to use a simulation modeling because it is impossible to construct an analytical model, where the system has a non-linear and random variables. When the simulation modeling applied, it is possible to describe the actual model of the educational system, using as the basis for the experimental work.

Thus, since a universal model of education management is absent and, moreover, due to its multivariativeness, nonlinearity and significant feedback effects, it is unlikely to be built. It is necessary to implement a program of design, construction and implementation of alternative models and development scenarios of an educational management system at all levels using the situational approach and simulation modeling. Stages of implementation of such a program are shown in figure 4.

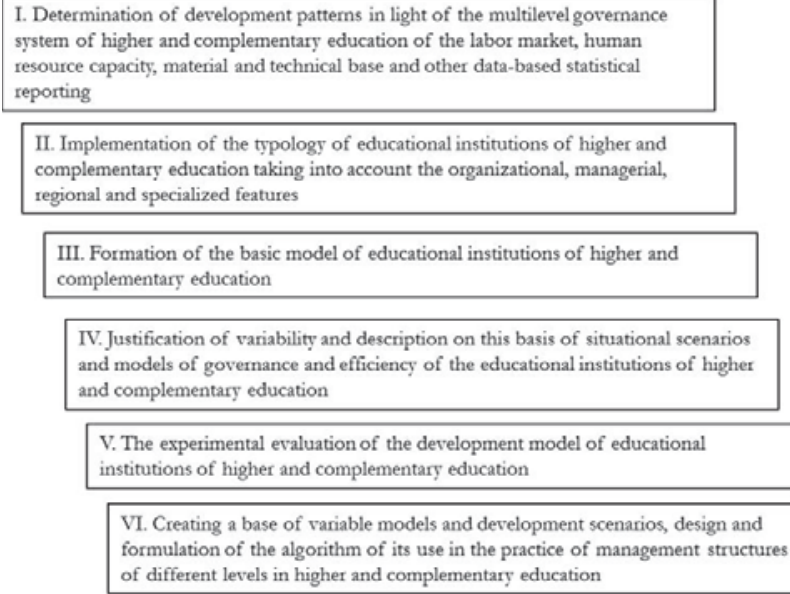

II. Implementation of the typology of educational institutions of higher and complementary education taking into account the organizational, managerial, regional and specialized features

III. Formation of the basic model of educational institutions of higher and complementary education IV. Justification of variability and description on this basis of situational scenarios
and models of governance and efficiency of the educational institutions of higher
and complementary education

V. The experimental evaluation of the development model of educational institutions of higher and complementary education

VI. Creating a base of variable models and development scenarios, design and formulation of the algorithm of its use in the practice of management structures of different levels in higher and complementary education

Figure 4. Program implementation stages

With regard to the expected results of the work, it should be noted that, firstly, at the present stage of societal development and in the context of the educational system modernization, these issues are of independent theoretical value. The practical results are in the specification of development scenarios of the higher educational institutions of various types, algorithmization of the selection process of these scenarios and in developed recommendations of their implementation, including the diversity of management aspects.

\section{References}

Barber, M., Donnelly, K., \& Rizvi, S. (2012). Oceans of innovation: The Atlantic, the Pacific, global leadership and the future of education. [Online] Available: http://www.ippr.org/publication/55/9543/oceans-of-innovation-the-atlantic-thepacific-global-leadership-and-thefuture-of-education. (October 12, 2015).

Burov, V.V., Parfenov, R.V., \& Remorenko, I.M. (2014). On modern technologies of citizens' participation in decision formulation in the sphere of education. Journal of Siberian Federal University. Series: Humanities, 49 (12), 2078-2088.

Clark, B.R. (2011). The system of higher education: academic organization in cross-national perspective. Moscow: Izdatelstvo.

Dneprov, E.D. (2006). The priorities of educational policy in the" Concept of modernization of Russian education "and the need to correct 
them. Current Pediatrics, 5(5), 5.

De Corte, E. (2014). Evaluation of Universities in Western Europe: From Quality Assessment to Accreditation. Educational Studies Moscow/Noprosy obrazovaniya, 4, 36-57.

Kuzminova, J.I., Semenov, D.S., \& Froumin, I.D. (2013). Unfinished transition from the State Planning Commission - to the master plan. Notes of the Fatherland, 4, 85-98.

Audebrand, L.K. (2010). Sustainability in Strategic Management Education: The Quest for New Root Metaphors. Academy of Management Learning \& Education, 9(3), 413-428.

Starik, M., Rands, G., Marcus, A.A., \& Clark, T.S. (2010). From the Guest Editors: In Search of Sustainability in Management Education. Academy of Management Learning \& Education, 9(3), 377-383.

Popov, L.E., Postnikov, S.N., Kolupaeva, S.N., \& Slobodskoi, M.I. (2015). Natural Resources and Technologies in Educational Activities: Education in times of accelerated technological development. Cambridge: Cambridge International Science Publishing Limited.

Schedrovitsky, P.G. (2001). Tomsk lectures on management (1998-2000). Tomsk: TSU.

Titova, N.L. (2011). Strategies for hierarchical organizations (for example, universities). University Management: Practice and Analysis. $5,24-30$. 